\title{
MPs and Audiences on Social Media during Emergencies: Automatic and Manual Content Analyses of Facebook Posts
}

\author{
Nili Steinfeld ${ }^{1}$ and Azi Lev-On ${ }^{1}$ \\ ${ }^{1}$ Ariel University, Ariel, Israel \\ nilisteinfeldegmail.com
}

\begin{abstract}
The social media channels of the members of parliament (MPs) are significant arenas through which communication between the public and national leaders occurs. This is the first paper to explore how these channels function during emergencies. We present findings from a mixed-method study of automatic and manual content analysis of a unique dataset of all posts in Israeli MPs' Facebook pages during the $19^{\text {th }}$ Israeli parliament. We compare the scope of posting, engagement with posts, and the content in MPs' Facebook pages during "ordinary" periods and an "emergency" period, focusing on the 2014 Israel/ Gaza war. Findings present MPs' social media pages as key hubs of information and interaction between MPs and audiences in emergencies, even more so than during ordinary periods. MPs' social media pages involve significantly more posts, and engagement with posts, during emergencies, and the content in them becomes more emotional, less personal and focused on the emergency situation and the national leaders responding to it.
\end{abstract}

Keywords: Emergencies, Facebook, MPs Facebook Pages, New Media, Social Media.

\section{$1 \quad$ Literature Review}

\subsection{Media in Emergencies}

The media are the source of many uses and gratifications. The two main gratifications emerging as most significant in a considerable portion of the studies are cognitive and social. Additional gratifications found in the relevant and popular studies range from recognition, status, and professional advancement to expression, individual and generalized reciprocation, leisure, escapism, fun, entertainment, arousal, and more $[1,2]$.

The media also plays a significant role in the framing of pubic issues. Frames can be described as central organizing ideas or story lines [3], which hold the potential to shape individual understanding and opinion pertaining to an issue by emphasizing specific elements or features relating to the broader picture in a manner which pro- 
motes a particular problem, definition, causal interpretation, moral evaluation and/or treatment recommendation [4].

The significance of media usage and framing may be of particular importance during emergencies and crises; when needs are intensified and become more acute on one hand, and on the other hand, the scope of information generation and circulation becomes more rapid compared to ordinary times [5,6]. Hence, people may find it increasingly difficult to make sense of the situation in its entirety and generate a clear picture of the state of affairs. Uncertainty and risks may cause anxiety, stress, anger and even depression stemming from a diminished sense of security and stability resulting from people's lack of information or control. Indubitably, studies demonstrate that the perceived importance of the media, and the enhanced scope of needs, which media are expected to fulfill significantly, increase during times of emergency [5].

\subsection{Online Social Media in Emergencies}

The contemporary media ecology is highly dynamic. New media channels, including major news websites, online social media and mobile applications, have become established means for generating and consuming content alongside the traditional mass media.

These vicissitudes are evident in Israel, in which data for the current study were collected. Israel has been the world leader with regards to the percentage of the population who uses Facebook and with regard to the average amount of time users spend on Facebook [7]. Furthermore, Israel was ranked $15^{\text {th }}$ in the World Economic Forums Networked Readiness Index of 2013 [8]. Between 65\%-85\% of mobile phone owners have smartphones; $54 \%$ of Israelis access the Internet through their smartphones [9].

These transformations are evident during emergencies as well. Studies on the use of new media in emergencies point to the centrality of such channels $[6,10]$. In a study of media usage during the Israel/Gaza war (2014), it was found that mass media channels remain dominant with respect to "top-down" information dissemination, nevertheless when it comes to "bottom-up" requests and provision of assistance, selfexpression and keeping in touch, social and mobile tools, especially WhatsApp, are dominant [5].

Facebook played a unique role in communications during the war. On the one hand, Facebook was used to promote collaborative initiatives, such as campaigns to participate in funerals of soldiers who had no immediate family in the country (lonesoldiers), visit wounded soldiers in hospitals, and/or organize and send packages to soldiers at the front, among others. On the other hand, Facebook became a prominent platform of violent discourse, for case in point, boycotts (for example of artists who protested against the war), and many "unfriendings" between people who disagreed with each other [11].

\subsection{Patriotism and Rallying around the Flag during Emergencies}

An additional phenomenon that typically occurs in the mainstream media during emergencies is its patriotic enthusiasm, and focus on national symbols and national leaders [12]. Indeed, academic literatures that study communication patterns in wars 
and significant security crises (such as the first and second Palestinian uprisings) in the Israeli context $[13,14,15,16]$ demonstrate a consistent pattern in which the mainstream media changes from a critical tone to a tone which emphasizes the in-groups at the extent of the out-groups and visually places more focus on national symbols and leaders, compared to ordinary times. The enhanced and more positive exposure of the public to its leaders in emergency times is typically followed by an increase of public trust in its leaders (i.e. the "rallying around the flag" effect [17]).

Note that the enhanced and positive coverage of the leaders tends to dissolve following a period of time. If the war lasts for an extended period of time, then typically voices that are critical of the causes of fighting, strategies and length of fight, emerge. Whilst this phenomenon occurred prior to the rise of new media, some argue [18] that this increases due to the sheer quantity of contemporary media channels, their availability to the public, and the rising ability of publics to participate in conversations about the fighting (for case in point, through online forums and user comments, and contemporarily social media platforms such as Facebook and WhatsApp).

\subsection{Contact between Politicians and Audiences through Social Media}

As social media takes a more prominent place in the media environment in general and during emergencies in particular, it is conceivable that contact between MPs and the public during emergencies may shift more and more on social media as well.

Many regard the Internet in general and social media specifically as useful tools for assisting parliamentarians to maintain a continuing dialogue with their constituents and the general public $[19,20]$. Whereas in the past, MPs relied on the mainstream media for coverage and exposure, contemporarily they can use their social media pages to interact with audiences directly, cutting out traditional intermediaries (such as parties) and the mass media [21]. Indeed over the past few years, it has become evident that presence in key social media arena's such as Facebook, becomes mandatory for politicians. In this current study, we found that 106 out of 120 MPs from the Israeli parliament maintain a Facebook page, sometimes with extensive activity.

MPs' social media channels have thus become central information and conversation media tools for various agents, including MPs themselves, journalists, as well as the general public. While studies demonstrate that this assertion may hold during ordinary times, it can arguably hold in emergencies as well. Nevertheless, the literature about new and social media usage in emergencies focus almost exclusively on how bureaucracies make use of these channels in order to advance and implement their policies, and how citizens use these in order to realize their needs. There are almost no studies characterizing the public discourse in central social media arenas in emergencies in general (for one exception see [22]), and in MPs' social media channels vis-à-vis the public in particular.

A small number of studies have looked at the content of posts by politicians which become more popular compared to others [23]. It appears that generally, emotion acts as a predictor of social media contents potential popularity. Studies examining the virality of Twitter tweets suggest that emotion, whether positive or negative, affects tweets' virality with the most retweeted ones being tweets expressing some sentiment 
or another [24,25]. More specifically, news content was found to be more viral when it was negative, and social content was most viral when drafted positively [26].

Since MPs' social media channels are significant arenas through which communication between the public and national leaders takes place in ordinary times and arguably during emergencies as well, this study makes a unique contribution to understanding the scope and framing of public activity during times of emergency.

\subsection{The Israel/Gaza War, 2014}

The Israel-Gaza War of 2014 has been the longest military operation ever waged by the State of Israel. The immediate background to the operation was the kidnapping (on June 11th) and murder of three Israeli teenagers by members of the Palestinian organization Hamas. The victims' bodies were found nearly three weeks later. This period was characterized by an increasing frequency of rockets fired from Gaza at civilian populations in southern Israel in June 2014.

The military response quickly escalated into a full-scale military operation that commenced on July 7th, 2014 and lasted 50 days. During this period, rocket firing was frequently carried out towards civilian population in the communities surrounding the Gaza strip, the Southern parts of Israel and beyond. A total of 3,600 rockets and mortars landed in Israel, 224 of which landed in urban areas [27]. During the operation, 67 Israeli soldiers and 5 civilians were killed and some 1,620 soldiers and 837 civilians were injured. On the Palestinian side, 2,203 Palestinians were killed, and over 11,000 Palestinians were injured.

\section{Research Questions}

The study investigates the interaction between citizens and MPs on Facebook, by analyzing posts content and engagement. The following research questions focus on a comparison between ordinary times and times of emergency, with the aim to illustrate how direct communications between MPs and citizens are influenced by crisis and whether they conform to previous observations on media in times of emergency.

\subsection{Publication and Engagement during Emergency and Ordinary Times}

RQ1. Are there differences in the scopes of publication and user engagement with posts in MPs' pages during emergency and ordinary times?

H1. We expect to find an increase in post publication rate and user engagement with politicians' posts during times of emergency, as users may be inclined to use MPs' social media platforms more intensely and focus more attention on political messages compared to ordinary times, aiming at satisfying their increasing needs $[4,5]$.

\subsection{Content of Posts Published during Emergency and Ordinary Times}


RQ2. Are there differences between posts published by politicians during emergency and ordinary periods in terms of discussing emergency issues?

H2. We expect that posts published during times of emergency would be significantly more oriented towards discussions regarding the national emergency, on-topic, and related to the current state of affairs.

RQ3. Are there differences in the proportion of personal posts published by politicians during times of emergency and ordinary periods?

H3. As emergency periods are characterized by a greater sense of patriotism and emphasis of national symbols, we expect to see less personal stories in politicians' posts during times of emergency.

\subsection{Sentiment and Tone of Posts Published during Emergency and Ordinary Times}

RQ4. Are there differences in sentiment of posts published by politicians during emergency and ordinary periods?

H4. We expect posts to be more negative and less positive during times of emergency when compared to ordinary periods.

RQ5. Are there differences in the level of criticism and support expressed in posts published by politicians during national emergency periods compared to ordinary periods?

H5. We expect to find posts published by politicians during times of emergency to express more support, foremost towards groups most affected by the emergency situation. However, as extended periods of emergency may be characterized by controversy among politicians regarding goals and operations conducted and not conducted by the state, we also expect to find an increase in criticism as well.

\subsection{Textual Differences between Posts Published during Emergency and Ordinary Times}

RQ6. What are the prominent terms in the texts of politicians' posts, and are there terms that specifically dominate posts published during emergency periods?

\section{$3 \quad$ Methodology}

A list of all 120 members of the 19th Israeli parliament (beginning February 5th, 2013, until December 9th, 2014) was composed based on data from the parliament's website. To locate the official Facebook page of each MP, Every MPs' page in the 
parliament website was scanned for a link to the MPs formal Facebook page. This was followed by a search with Google's search engine and finally within Facebook, entering the name of each MP in Hebrew, Arabic, and English, Israel's three official languages. 106 MPs' formal Facebook pages were found and included in the study.

All 106 pages were scraped using Netvizz, a Facebook app developed by Digital Methods Initiative labs ${ }^{1}$. We used the application to extract and archive all of the posts published by either the pages or users during the entire 21-month period of the 19th parliament. In total, our dataset included 441,974 posts. Netvizz automatically attaches the following information to every post: publication date, post origin (page or a user- anonymized), post text and various engagement measures, i.e. number of likes, comments, and shares that the post received. It should be noted that during the period examined, Facebook had not yet introduced reactions, therefore the above engagement indices are the only ones relevant for the posts extracted for this study. As the aim of the study is to examine the Facebook activity of all Israeli MPs throughout an entire service of the parliament, the period of the 19th parliament was chosen for the extraction of the data (the 20th parliament is still at service at the time of writing).

To analyze the posts, we used a combination of automatic and manual content analyses. The automatic analysis is based on information retrieved by Netvizz, while the manual coding was conducted on a sample of each MP's bi-monthly, most popular post. In order to generate the sample, we divided the entire period of analysis into periods of two months. Then, for each of the periods, and for each MP, we sampled the leading post/s in terms of number of likes. The decision to look at number of likes rather than number of comments or shares was made on account of "likes" being the preferred and most common type of user engagement with posts in the dataset, engaging more users than other types of engagement. The most-liked post sample, which consisted of 994 posts, included posts authored by MPs only, as the focus of this study surrounds content posted by MPs which is most favorable by users. The sampling method described above enabled the equal representation of each MP, throughout the entire period examined.

Manual coding was conducted by five coders who were trained by the researchers. Repeated training sessions were conducted for categories that achieved less than $90 \%$ reliability, until inter-coder reliability of $90 \%$ was achieved in all categories. The content and tone of posts were coded according to the following categories:

- Discussing emergency issues.

- Personal Story (e.g. "Joyful times: A new granddaughter was born to our family").

- Criticism or support of a person or entity. A post could be either critical (e.g. "The haughty government led by Netanyahu, Bennet and Lapid"), supportive (e.g. "PM Netanyahu's decision is a brave one"), or neutral- does not include criticism or support or includes both equally.

- Object of criticism/support (e.g. another politician by name, a formal entity in the parliament, citizens, publics, non-parliamentary public figures, public figures outside of Israel, Media organizations)

\footnotetext{
${ }^{1}$ We thank Digital Methods Initiative and the developer, Bernhard Rieder, for the use of this tool
} 
- Positive tone (e.g. "We have finally and successfully passed the legislation")

- Negative tone (e.g. "Terrorists belong behind bars and not at the parliament")

For the analysis of prominent terms we created two corpuses: The "ordinary" corpus included the texts of all posts published during the ordinary period, and the "emergency" corpus included the texts of all posts published during the emergency period (between June $11^{\text {th }}$ and August $26^{\text {th }}, 2014$ ). For each corpus, we used n-gram extraction tools to extract co-occurring words frequencies in the texts. ${ }^{2}$ The tool implements an algorithm that extracts the number of co-occurrences of words in the text [28]. We configured the tool to extract terms containing between two and five words, which appear at least 50 times in the texts. For a comparison of shared and different n-grams between the two corpuses, we used the online tool Compare Lists ${ }^{3}$ developed by the Digital Methods Initiative labs which compares two lists of keywords for common and different words in each list.

\section{$4 \quad$ Findings}

\subsection{Publication and Engagement during Emergency and Ordinary Times}

As Table 1 demonstrates, $16.3 \%$ of the posts in the dataset (71847 out of 441974 posts) were published during the emergency period. This proportion is slightly larger than the proportion of this period in the dataset (76 days out of 673 which are $11.3 \%$ ), suggesting that this period has been slightly more active in terms of Facebook posting. But when looking at posts published by politicians only (excluding user-authored posts) it appears that politicians are not more active during times of emergency. In fact, the proportion of posts published by politicians matches exactly the proportion of the period in the dataset: $11.4 \%$ (4350 out of 38242 ) of politicians posts were published during the period of the kidnapping and the military operation.

Due to these measures' highly skewed distribution, a series of Mann-Whitney tests were conducted to test for significant differences in engagement between the two time periods. The tests confirmed the differences between posts published by MPs only during emergency and ordinary times, with emergency posts receiving significantly more likes $(\mathrm{U}=53835203, \mathrm{p}<.001)$, more comments $(\mathrm{U}=58073772.5, \mathrm{p}<.001)$ and more shares $(55801516.5, \mathrm{p}<.001)$ than posts published by MPs during ordinary times. The differences are also significant for all of the posts published by users and by MPs (For likes: U=10973979370, p<.001; For comments: U=10977161638.5, $\mathrm{p}<.001$; and for shares: $13038566507.5, \mathrm{p}<.001$ ). These findings support H1.

\footnotetext{
2 https://homepages.inf.ed.ac.uk/lzhang10/ngram.html. We thank the developer, Zhang Le, for the use of the tool.

3 https://tools.digitalmethods.net/beta/analyse/
} 
Table 1. Posts and Engagement with Posts during Emergency and Ordinary Periods

Entire period Ordinary $(88.7 \%)$ Emergency $(11.3 \%)$

\begin{tabular}{|c|c|c|c|}
\hline $\begin{array}{lll}\text { Posts (users and } \\
\text { MPs) }\end{array}$ & 441974 & $370108(83.7 \%)$ & $71847(16.3 \%)$ \\
\hline Posts (MPs only) & 38242 & $33892(88.6 \%)$ & $4350(11.4 \%)$ \\
\hline Likes (all posts) & $\begin{array}{l}\mathrm{M}=83.85 \\
\mathrm{SD}=970.53\end{array}$ & $\begin{array}{l}\mathrm{M}=72.26 \\
\mathrm{SD}=774.22 * * *\end{array}$ & $\begin{array}{l}\mathrm{M}=143.53, \\
\mathrm{SD}=1643.81 * * *\end{array}$ \\
\hline Likes (MPs posts) & $\begin{array}{l}M=928.4 \\
S D=3164.8\end{array}$ & $\begin{array}{l}\mathrm{M}=748.53 \\
\mathrm{SD}=2439.48 * * *\end{array}$ & $\begin{array}{l}\mathrm{M}=2329.83, \\
\mathrm{SD}=6283.19 * * *\end{array}$ \\
\hline $\begin{array}{l}\text { Comments (all } \\
\text { posts) }\end{array}$ & $\begin{array}{l}M=8.81 \\
S D=95.7\end{array}$ & $\begin{array}{l}\mathrm{M}=8.11, \\
\mathrm{SD}=82.96 * * *\end{array}$ & $\begin{array}{l}\mathrm{M}=12.43 \\
\mathrm{SD}=144.45^{* * *}\end{array}$ \\
\hline $\begin{array}{l}\text { Comments (MPs } \\
\text { posts) }\end{array}$ & $\begin{array}{l}M=89.18 \\
S D=312.79\end{array}$ & $\begin{array}{l}\mathrm{M}=75.35 \\
\mathrm{SD}=263.1 * * *\end{array}$ & $\begin{array}{l}\mathrm{M}=196.94 \\
\mathrm{SD}=554.78 * * *\end{array}$ \\
\hline Shares (all posts) & $\begin{array}{l}M=6.73 \\
S D=193.76\end{array}$ & $\begin{array}{l}\mathrm{M}=5.1 \\
\mathrm{SD}=76.43 * * *\end{array}$ & $\begin{array}{l}\mathrm{M}=15.09 \\
\mathrm{SD}=448.07 * * *\end{array}$ \\
\hline $\begin{array}{l}\text { Shares } \\
\text { posts) }\end{array}$ & $\begin{array}{l}\mathrm{M}=75.94 \\
\mathrm{SD}=652.3\end{array}$ & $\begin{array}{l}\mathrm{M}=53.99 \\
\mathrm{SD}=240.55^{* * *}\end{array}$ & $\begin{array}{l}\mathrm{M}=246.94, \\
\mathrm{SD}=1804.86 * * *\end{array}$ \\
\hline
\end{tabular}

$* * * \mathrm{p}<.001$

\subsection{Differences in Content of Posts Published during Emergency and Ordinary Times}

Turning to analysis of the 944 most-liked posts sample demonstrates significant and dramatic differences in content relating to emergency situations during the emergency period $(50 \%)$ compared to ordinary times $(3.4 \%)$, i.e. half of the preferred posts were related to the emergency situation. This supports $\mathrm{H} 2$. However, users also preferred posts which did not discuss the events half of the times, suggesting that politicians and users alike saw an importance in addressing other issues during that period.

Only $9.2 \%$ of politicians' posts published during the time of national emergency included a personal angle of story (unrelated to politics), compared to $18.7 \%$ during ordinary times $\left(\chi^{2}=7.62, \mathrm{p}<.01\right)$. This finding supports $\mathrm{H} 3$.

Table 2 summarizes the significant differences found between politicians' posts published during ordinary and emergency periods.

\subsection{Differences in Sentiment and Tone of Posts Published during Emergency and Ordinary Periods}

Posts in the most-liked sample published during the emergency period are less positive $(47.9 \%$ vs. $62.5 \%)$ and more negative $(65.5 \%$ compared to $44.2 \%)$ compared to posts published during ordinary periods. These findings support $\mathrm{H} 4$. 
With respect to criticism and support, posts are more supportive during emergency $(28.9 \%)$ than during ordinary periods $(18.4 \%)$. In ordinary periods, support is targeted toward certain groups $(25 \%)$ followed by citizens $(20.7 \%)$ and non-parliamentary public figures (18.6\%). In emergency, support is first and foremost directed at citizens (46.3\%) followed by certain groups $(24.4 \%$, such as, for example, "the soldiers", or "residents of the south" living in areas suffering most from missile launches).

Criticism is also more prominent during emergency periods $(38 \%)$ compared to during ordinary periods $(30.1 \%)$, with criticism during ordinary periods directed mostly at other politicians by name $(19.2 \%)$, followed by non-parliamentary public figures $(17.9 \%)$, and during emergency, directed at other politicians $(33.3 \%)$ followed by, quite surprisingly, citizens (16.7\%). These findings support H5.

Table 2. Differences between content of ordinary and emergency posts

\begin{tabular}{|c|c|c|c|}
\hline Category & $\begin{array}{l}\% \text { of Emergen- } \\
\text { cy Posts }\end{array}$ & $\begin{array}{l}\% \text { of Ordi- } \\
\text { nary Posts }\end{array}$ & Differences \\
\hline Emergency & $50 \%$ & $3.4 \%$ & $\chi^{2}=271.59, p<.001$ \\
\hline Positive Sentiment & $47.9 \%$ & $62.5 \%$ & $\chi^{2}=10.62, p<.01$ \\
\hline Negative Sentiment & $65.5 \%$ & $44.2 \%$ & $\chi^{2}=21.83, p<.001$ \\
\hline Support & $28.9 \%$ & $18.4 \%$ & \\
\hline Criticism & $38 \%$ & $30.1 \%$ & \\
\hline $\begin{array}{l}\text { Neutral (No Criticism, No } \\
\text { Support) }\end{array}$ & $33.1 \%$ & $51.6 \%$ & $\begin{array}{l}\int \chi^{2}=1 \\
p<.001\end{array}$ \\
\hline Personal Story & $9.2 \%$ & $18.7 \%$ & $\chi^{2}=7.62, p<.01$ \\
\hline
\end{tabular}

\subsection{Textual Differences between Emergency Period Posts and Ordinary Posts}

Moving to an analysis of the prominent terms in each of the corpuses: the "ordinary" corpus, composed of the texts of all posts published during ordinary periods, and the "emergency" corpus, composed of texts of all posts published during the emergency period. We used the n-gram tool described above to extract prominent terms and compared ordinary and emergency prominent terms using the compare lists tool.

Ordinary Discourse. The list of frequent terms in the posts published during ordinary periods is led by two main figures: The Minister of Finance Yair Lapid, a former popular news anchor, recently entered into politics and the center of public attention throughout the study period, and the Prime Minister, Benjamin Netanyahu. The discourse is also dominated by direct applications to ministers ("Mr. Secretary") and expressions of demands ("I want"; "It's about time").

Emergency Discourse. The list of terms in the emergency corpus is led by a variety of terms supporting the Palestinians (e.g. "free Palästina" is no. 1 in the list, and "syrien"- no. 2). These are presumably the work of pro-Palestinian hacktivists who engaged in online attacks on officials' Facebook pages. The first terms unrelated to these messages are "Prime Minister", "the state of Israel" and "the Israeli People". Alike, "cease fire" is also prominent. 
Comparing between the corpuses. Some issues which are common in the discourse that evolves on politicians' pages in ordinary times, are set aside during emergencies. A clear example is the word "equality", an often used word in various terms in the discourse: "Equal rights", "Inequality", "Equal opportunities", "Gender equality", and the like. Altogether, the word "equal" appears in 73 phrases, all of them were extracted from the ordinary corpus. None of the prominent phrases of posts published during the emergency period included a reference to the notion of equality.

Another topic only raised in ordinary periods is minimum wage: All 34 phrases mentioning minimum wage ("(The) Minimum Wage", "Raising the Minimum Wage", "Minimum Salary", and similar) were extracted from the ordinary corpus, while none came up in the emergency corpus analysis. On the contrary, the emergency discourse revolves, first and foremost, around issues relevant to the crisis. The word "Hamas" is included in 98 phrases, 6 of which ("Hamas", "With Hamas" etc.) were extracted from both corpuses, while the rest were extracted from the emergency corpus only.

\section{$5 \quad$ Discussion and Conclusions}

MPs' social media arenas are significant channels through which communication between the public and national leaders occurs. Many studies analyzed the content, and engagement with it, occurring in such arenas during ordinary times. The current study is the first to analyze them in emergency times; focusing on the 2014 Israel/Gaza war.

Studying content and engagement pertaining to MPs social media arenas during emergencies is important as needs are intensified and become more acute on one hand, and on the other hand the scope of information generation and circulation becomes faster compared to ordinary times. Sites that function as information hub in "ordinary times", as MPs' social media channels do, can thus function in emergencies as hubs of information and discussion, and possibly even drivers of patriotism and ingroup collectivism, as the mainstream media tend to function in emergencies.

With more than 20,000 monthly posts and hundreds of thousands of comments, MPs' social media pages are definably a central hub for information circulation and discussion. While MPs themselves do not post more often during emergencies, there were certainly an increased number of posts on their pages during emergencies (i.e. users make many more posts to MPs pages during time of emergency, nonetheless MPs themselves do not). There is also significantly more engagement with these posts: posts made during emergencies gain significantly more likes, comments and shares than "ordinary times" posts.

Analysis of the content posted on MP pages during ordinary times and emergencies demonstrates that topics that lead the social media in "ordinary times" such as the discourse on equal rights gender equality, minimum wage and more, are neglected during emergencies, focusing on the emergency situation itself and the national leaders attending to it. MPs publish significantly less personal posts during emergencies, which further demonstrates how the collectivist spirit during national emergencies triumphs over MPs intention to present their "personal angle" online. Discourse seems to become more emotional, expressing more support (especially towards citizens, 
groups directly affected from the war and soldiers) and criticism (especially of politicians), demonstrating a more negative and less positive sentiment.

These findings indeed portray MPs social media arenas in emergencies as hubs of information and discussion, and as a patriotic and in-group collectivist arena. Future studies can compare these findings with findings from online social media arenas of public figures and entities in future emergencies in Israel and elsewhere.

\section{Acknowledgements}

The study was supported by the Institute for the Study of New Media, Politics and Society at Ariel University. We thank Michael Barmatz, Yinon Sarusi, Nadav Gelbert, Elnatan Grinwold, Reut Dodeles, Tehila Gelman and Salih Sawaed for their assistance in collecting and processing the data, and for Nomy Bitman and Candice Kotzen for their assistance with preparing the manuscript.

\section{References}

1. Lev-On, A.: Uses and gratifications: Evidence for various media. In: International Encyclopedia of Media Effects, ed. Patrick Roessler. Wiley-Blackwell, Hoboken, NJ (2017).

2. Sundar, S. S., Limperos, A. M. Uses and grats 2.0: New gratifications for new media. Journal of Broadcasting \& Electronic Media 57(4), 504-525 (2013).

3. Gamson, W.A., Modigliani, A.: The changing culture of affirmative action. In. Braungart, R.G (eds.), Research in political sociology, vol. 3, pp. 137-177. JAI Press, Greenwich, CT (1987).

4. Entman, R.M.: Framing: Toward clarification of a fractured paradigm. Journal of Communication 43, 51-58 (1993).

5. Lev-On, A., Uziel, V.: Live, visual, social, and mobile: Media ecology in emergencies and ordinary times. Online Information Review, 42 (2018).

6. Lev-On, A.: Communication, community, crisis: Mapping uses and gratifications in the contemporary media environment. New Media and Society 14(1), 98-116 (2012).

7. ComScore: It's a social world: Top 10 need-to-knows about social networking and where it's headed. www.comscore.com/it_is_a_social_world, last accessed 2016/3/17 (2011).

8. Bilbao-Osorio, B., Dutta, S., X Lanvin, B.: The global information technology report 2013: Growth and jobs in a hyperconnected world. http://www3.weforum.org/docs/WEF_GITR_Report_2013.pdf, last accessed 2016/3/17 (2013).

9. Mann, R., Lev-On, A.: Annual report: The media in Israel 2014: Agendas, uses and trends. Institute for the Study of New Media, Politics and Society, Ariel, Israel (2015).

10. Houston, J. B., Hawthorne, J., Perreault, M. F., Park, E. H., Goldstein Hode, M., Halliwell, M. R., ... Griffith, S. A.: Social media and disasters: A functional framework for social media use in disaster planning, response, and research. Disasters 39(1), 1-22 (2015).

11. John, N.A., Dvir-Gvirsman, S.: 'I don't Like you any more': Facebook unfriending by Israelis during the Israel-Gaza conflict of 2014. Journal of Communication 65(6), 953-974 (2015).

12. Waisbord, S.: Journalism, risk and patriotism. In: Zelizer, B., Allan, B. (eds.) Journalism after September 11, pp. 201-219. Routledge, New York (2002). 
13. Dor, D.: Newspapers under influence. Babel, Tel Aviv (2011).

14. Elbaz, S., Bar-Tal, D.: Dissemination of culture of conflict in the Israeli mass media: The wars in Lebanon as a case study. The Communication Review 19(1),1-34 (2016).

15. Neiger, M., Rimmer-Tsory, K.: The war that wasn't on the news:'In-group nationalism' and 'out-group nationalism' in newspaper supplements. Journalism 14(6), 721-736 (2013).

16. Neiger, M. Zandberg, E.: Days of awe: The praxis of news coverage of violent conflict. The European Journal of Mass Communication 29, 429-446 (2004).

17. Hetherington, M. J., Nelson, M.: Anatomy of a rally effect: George W. Bush and the war on terrorism. PS: Political Science \& Politics 36(1), 37-42 (2003).

18. Weimann, G.: The Israeli public's criticism of the media during the Lebanon War of 2006. University of Tel Aviv Press, Tel Aviv (2007).

19. Blumler, J. G., Coleman, S.: The Internet and democratic citizenship. Cambridge University Press, New York (2009).

20. Grossman, L.K.: The electronic republic: Reshaping democracy in the information age. Viking Penguin, New York (1995).

21. Bernhard, U., Dohle, M.: Local politics online: The influence of presumed influence on local politicians' online communication activities in Germany. Local Government Studies 41(5), 755-773 (2015).

22. Murai, S., Suzuki, T.:How the Japanese social media users discussed the Senkaku controversy. In: The dispute over the Diaoyu/Senkaku islands, pp. 169-199. Palgrave Macmillan, New York (2014).

23. Steinfeld, N., Lev-On, A.: Writing on the city wall: An analysis of popular municipal Facebook page posts. In: New Approaches, Methods and Tools in Urban E-Planning, ed. Carlos Nunes Silva, pp. 33-59. Hershey, PA, IGI Global (2018).

24. Lin, J. S., Peña, J.: Are you following me? A content analysis of TV networks' brand communication on Twitter. Journal of Interactive Advertising 12(1), 17-29 (2011).

25. Stieglitz, S., Dang-Xuan, L. Emotions and information diffusion in social media: Sentiment of microblogs and sharing behavior. Journal of Management Information Systems, 29(4), 217-248 (2013).

26. Hansen, L.K., Arvidsson, A., Nielsen, F. Å., Colleoni, E., Etter, M.: Good friends, bad news-affect and virality in twitter. In: Future information technology, pp. 34-43. Springer, Heidelberg (2011).

27. Ynet. August 27, 2014 Operation Protective Edge in numbers. https://www.ynetnews.com/articles/0,7340,L-4564678,00.html. Last accessed 2018/5/17.

28. Nagao, M., Mori, S.: A new method of N-gram statistics for large number of $\mathrm{n}$ and automatic extraction of words and phrases from large text data of Japanese. In: Proceedings of the 15th conference on Computational linguistics, vol. 1, pp. 611-615. Association for Computational Linguistics (2014) 